\title{
CORRECTION
}

\section{Correction to: Two-port robotic hysterectomy: a novel approach}

\author{
Gaby N. Moawad ${ }^{1} \cdot$ Paul Tyan $^{2}\left(\mathbb{D} \cdot\right.$ Elias D. Abi Khalil ${ }^{1}$
}

Published online: 26 May 2018

๑) Springer-Verlag London Ltd., part of Springer Nature 2018

\section{Correction to: Journal of Robotic Surgery} https://doi.org/10.1007/s11701-018-0797-2

In the original article, the co-author's given name and family name has been published incorrectly. The correct given name should be Elias D and the correct family name should be Abi Khalil.

The original article can be found online at https://doi.org/10.1007/ s11701-018-0797-2.

Paul Tyan

paul.ib.tyan@gmail.com

1 Department of Minimally Invasive Gynecologic Surgery,

George Washington University, Washington, DC, USA

2 Department of Obstetrics and Gynecology,

George Washington University, 900 23rd St NW,

Washington, DC 20037, USA 